\title{
Saudi Nurses Perception regarding Patient Safety in a Major Tertiary Hospital
}

\author{
Budour Bandar Alotaibi ${ }^{*}$, Alanoud Essam Almadani², Olfat Salem ${ }^{3}$ \\ ${ }^{1}$ Prince Sultan Military Medical City, Riyadh, KSA \\ ${ }^{2}$ Al-Iman General Hospital, Riyadh, KSA \\ ${ }^{3}$ King Saud University, Riyadh, KSA \\ Email: ^botaibi@psmmc.med.sa
}

How to cite this paper: Alotaibi, B.B. Almadani, A.E. and Salem, O. (2020) Saudi Nurses Perception regarding Patient Safety in a Major Tertiary Hospital. Open Journal of Nursing, 10, 657-664. https://doi.org/10.4236/ojn.2020.107046

Received: March 15, 2020

Accepted: June 27, 2020

Published: June 30, 2020

Copyright (c) 2020 by author(s) and Scientific Research Publishing Inc. This work is licensed under the Creative Commons Attribution International License (CC BY 4.0).

http://creativecommons.org/licenses/by/4.0/

\section{(c) (i) Open Access}

\begin{abstract}
Background: The absence of patient safety culture among nurses has been linked to increased errors and higher level of mortality and morbidity among patients. Higher culture of patient safety has been shown to be associated with better patient outcomes, and the implementation of improvements in organizational and safety culture enhances quality in healthcare. Aim: The main aim of this study is to assess the perception of nurses regarding patient safety among nurses at prince sultan military medical city in Saudi Arabia. Materials and Methods: Cross-sectional design was applied in this study among nurses who are working at prince sultan military medical city in Riyadh, Saudi Arabia. Sample was 215 nurses, selected by convenience sampling method. The Hospital Survey on Patient Safety Culture (HSOPS) survey was used in the current study to collect data. Data have been collected within seven weeks. Statistical package for social sciences has been used to analyze data using descriptive statistics and inferential statistics such as Independent sample $t$ test and One-Way ANOVA. Results and Conclusion: The results can only be useful if data analysis is described. The highest domain of their perception was illustrated in "Hospital management support for patient safety" with a mean of 3.68 out of 5.0, while, the lowest mean for their perception was in the domain of "Teamwork across hospital units" with a mean 2.62. The total mean of nurses' perception regarding patient safety was 3.19 out of 5.0. Also, there was a significant difference in the mean level of nurses' perception of patient safety with regard to nurses' gender. Encouraging patients' safety culture among nurses is strongly recommended through effective communication and providing feedback.
\end{abstract}

\section{Keywords}

Perception, Patient, Safety, Hospital 


\section{Introduction}

Globally, government engagement, and intervention in patient safety management in the health care environment is increasing [1]. The concern for patient safety was reaffirmed with the publication of the report "to err is human" by the Institute of Medicine in the United States of America, which estimated the annual occurrence of 44,000 and 98,000 deaths of patients in hospitals, occasioned by errors associated with health care, which could be prevented [2].

Most practitioners are already trying to do the right thing to prevent errors; the old strategy of punishing practitioners when things go wrong is unlikely to be effective for improving patient safety [3]. In health environments, behaviors and attitudes shape the culture of each organization [4].

The sharing of beliefs, values, and attitudes related to the patient's safety culture influences the outcome and organizational aspects [5]. Higher culture of patient safety has been shown to be associated with better patient outcomes. Quality in hospital services means providing the patient with multidisciplinary care at minimal risk. Therefore, implementing improvements in organizational and safety culture enhances quality [6].

Most common causes of adverse events include failures in communication during handoffs, unclear communication in critical situations, lack of protocols, lack of knowledge of products or unavailability of equipment, and ineffective education [7].

In Saudi Arabia, it has been revealed that the majority of nurses perceived a positive patient safety culture [8]. Moreover, the study of Eldeeb et al. [9] in Saudi Arabia showed that the majority of nurses had low level of patient safety, and the majority of them did not formally report adverse events [9]. There are no studies on patient safety in prince sultan military medical city in Riyadh. So, the main aim of this study was to assess the perception of nurses regarding patient safety among nurses at prince sultan military medical city in Saudi Arabia.

\section{Materials and Methods}

\subsection{Design, Sample and Sampling}

This study has been conducted between the period of February and June 2019. The study adopted a quantitative cross-sectional design which was carried out at prince sultan military medical city in Riyadh, Saudi Arabia. The study population consisted of the nurses who are working in a major tertiary hospital in Saudi Arabia. The sample size was be calculated using Thompson formula [confidence limit $=0.05$, power $=0.8]$ based on the study population. After calculation, sample was 215 nurses, in which 183 (85.11\%) nurses have responded to the study questionnaire. Convenient sampling was applied to recruit the nurses who are working in the hospital by distributing the questionnaires on the available nurses within departments who have met the inclusion criteria. Formally employed Saudi nurses who are working in all of the departments in the above mentioned hospital and interested to participate in this study have been in- 
cluded.

\subsection{Study Instrument}

The Hospital Survey on Patient Safety Culture (HSOPS) survey developed by Hannah et al. (2008) was used in the current study, there was no need to get the permission to use this questionnaire since it is available for public use. The study questionnaire consisted of eight parts as follow: 1) Demographic characteristics of the respondents such as their age, gender, education, and experience, 2) Supervisor support, 3) Organizational learning, 4) Teamwork within units, 5) Communication openness, 6) Staffing levels, 7) Management support, and 8) Teamwork across units. The highest mean score for each domain is 5.0, while the lowest one is 1 .

Some of questions in this questionnaire have Likert scale which has a 5-points as ( $1=$ strongly disagree, $2=$ disagree, $3=$ neither agree nor disagree, $4=$ agree, and $5=$ strongly agree). Other questions are measured on 5 -points as $(1=$ never, $2=$ rarely, $3=$ sometimes, $4=$ most of the time, and $5=$ always). The majority of questions are positively worded, other questions are negatively warded; hence the code of these questions was inverted. Positive perception of patient safety was considered if the domain mean score is 3.0 or higher, or if the total mean score for all of domains is 3.0 or higher; otherwise it has been considered negative perception.

\subsection{Ethical Consideration}

The researchers were committed to all ethical considerations which have been required to conduct this study. An approval was obtained from faculty of nursing at King Saud University, and prince sultan military medical city. Also, approval from IRB was gathered to start actual data collection. Ethical consent was obtained from the participants before their participation.

\subsection{Data Analysis}

Data analysis was done using Statistical Package for Social Sciences. The data was gathered, appropriate entry method was conducted, data cleaning then doing frequency tables for all study variables. Mean and standard deviation was calculated. Statistical tests which were used include independent sample t test, and One-Way ANOVA. One-Way ANOVA was used to detect the differences in the level of nurses' perception with regard to their experience and their age groups.

\section{Results and Discussion}

The study sample of this study after calculation consisted of 215 nurses, in which $183(85.11 \%)$ have responded to participate. Table 1 shows that more than half (74.3\%) of the participants in the current study are females, while $25.7 \%$ of them are males. Also, the mean of nurses' age is 30.23 years old; after classification of 
Table 1. Sample distribution according to the participants' gender, age groups, educational level, and experience $(\mathrm{n}=183)$.

\begin{tabular}{|c|c|c|}
\hline Variables & Number & Percentage (\%) \\
\hline \multicolumn{3}{|c|}{ Gender } \\
\hline Male & 47 & 25.7 \\
\hline Female & 136 & 74.3 \\
\hline Total & 183 & 100.0 \\
\hline \multicolumn{3}{|c|}{ Age groups } \\
\hline$<25$ years & 16 & 8.7 \\
\hline $25-30$ years & 94 & 51.4 \\
\hline $31-39$ & 68 & 37.2 \\
\hline$>39$ years & 5 & 2.7 \\
\hline Total & 183 & 100.0 \\
\hline \multicolumn{3}{|c|}{ Mean \pm SD $30.23 \pm 4.53$} \\
\hline \multicolumn{3}{|c|}{ Educational level } \\
\hline Diploma & 78 & 42.6 \\
\hline Bachelor & 83 & 45.4 \\
\hline Postgraduate & 22 & 12.0 \\
\hline Total & 183 & 100.0 \\
\hline \multicolumn{3}{|c|}{ Experience } \\
\hline$<5$ years & 43 & 23.5 \\
\hline $5-10$ years & 108 & 59.0 \\
\hline $11-15$ years & 28 & 15.3 \\
\hline$>15$ years & 4 & 2.2 \\
\hline Total & 183 & 100.0 \\
\hline & Mean \pm SD $7.02 \pm 3.78$ & \\
\hline
\end{tabular}

their ages, the table shows that $51.4 \%$ of the study participants are $25-30$ years old, $37.2 \%$ are 31 - 39 years old.

Regarding the educational characteristics of the nurses, the table shows that $45.4 \%$ of the study participants have bachelor degree, and $42.6 \%$ have diploma, while $12.0 \%$ of them have master. Additionally, 59.0 of the nurses are working for 5 - 10 years and $23.5 \%$ of them are working for less than 5 years.

Regarding the nurses' perception of patient safety, the study results revealed that the highest domain of their perception was illustrated in "Hospital management support for patient safety" with a mean of 3.68 out of 5.0, followed by "Organizational learning-continuous improvement" with a mean of 3.66, while, the lowest mean for their perception was in the domain of "Teamwork across hospital units" with a mean 2.62. The total mean of nurses' perception regarding patient safety was 3.19 out of 5.0 (Table 2). 
Table 2. Nurses' perception about patient safety.

\begin{tabular}{|c|c|c|c|}
\hline Perception domain & $\mathrm{No}^{\circ}$ items & Mean & SD \\
\hline 1. Overall perceptions of safety & 4 & 3.03 & 0.56 \\
\hline 2. Frequency of events reported & 3 & 2.95 & 1.06 \\
\hline $\begin{array}{l}\text { 3. Supervisor/manager expectations \& actions promoting } \\
\text { patient safety }\end{array}$ & 4 & 3.11 & 0.76 \\
\hline 4. Organizational learning-continuous improvement & 3 & 3.66 & 0.88 \\
\hline 5. Teamwork within units & 4 & 3.20 & 0.71 \\
\hline 6. Communication openness & 3 & 3.20 & 0.71 \\
\hline 7. Feedback and communication about errors & 3 & 3.61 & 0.85 \\
\hline 8. Non-punitive response to error & 3 & 3.03 & 0.93 \\
\hline 9. Staffing & 4 & 3.04 & 0.72 \\
\hline 10. Hospital management support for patient safety & 3 & 3.68 & 0.82 \\
\hline 11. Teamwork across hospital units & 4 & 3.10 & 0.63 \\
\hline 12. Hospital handoffs \& transitions & 5 & 2.62 & 0.92 \\
\hline Total & 43 & 3.19 & 0.44 \\
\hline
\end{tabular}

The study results showed that there is a significant difference in the mean level of nurses' perception of patient safety between male and female nurses, in which female nurses have significantly higher level of perception of patient safety than males [Table 3]. Furthermore, there is no significant difference in the mean level of nurses' perception of patient safety with regard to their age groups, experience level, and educational level ( $\mathrm{p}>0.05)$ [Table 4].

The current study results are not consistent with the results of Eldeeb et al. [9] which revealed that more than half of nurses do not formally report adverse events whether a mistake is made but there is no any potential to harm the patient or a mistake caught and corrected before affecting the patient even if the mistake could harm the patient respectively. Moreover, the results of the present study are not consistent with the results of Aboshaiqah and Baker [8] which has been conducted in Saudi Arabia; which revealed that $58.0 \%$ of the study participants reported mistakes and correct them before affecting the patient. Meanwhile, $55.3 \%$ of nurses reported a mistake when it is made and no potential to harm the patient and $68.1 \%$ reported a mistake when it is made and could harm the patient but does not.

Regarding organizational learning, the result of the current study is lower than what has been revealed in the study of Alshammari et al. [10] in Saudi Arabia, which revealed that the total mean score of the domain of organizational learning is 3.98. On the other hand, this result is higher than what has been revealed in the study of Okuyama et al. [11] which revealed that the domain of "Organizational learning-continuous improvement" was 2.57 (51.5\%).

Regarding the total perception of patient safety culture among study participants in the current study, all of the above mentioned domains were considered 
Table 3. Differences in the level of nurses perception about patient safety with regard to their gender.

\begin{tabular}{cccccc}
\hline Gender & $\mathbf{n}$ & Mean & SD & t statistics (df) & p value $^{1}$ \\
\hline Male & 47 & 3.08 & 0.38 & & \\
Female & 136 & 3.23 & 0.46 & $-2.208(94.31)$ & 0.030 \\
\hline
\end{tabular}

${ }^{1}$ Independent sample $\mathrm{t}$ test.

Table 4. Differences in the level of nurses perception about patient safety with regard to their demographic factors.

\begin{tabular}{cccccc}
\hline Variable & $\mathbf{n}$ & Mean & SD & F (df) & p value $^{1}$ \\
\hline$<25$ years & 16 & 3.23 & 0.51 & & \\
25 - 30 years & 94 & 3.15 & 0.46 & & \\
31 - 39 years & 68 & 3.23 & 0.41 & & \\
$>39$ years & 5 & 3.39 & 0.17 & & \\
& & Educational level & & & \\
Diploma & 78 & 3.14 & 0.45 & & 0.304 \\
Bachelor & 83 & 3.21 & 0.45 & $1.197(2,180)$ & \\
Master & 22 & 3.30 & 0.36 & & \\
& & Experience & & & \\
$<5$ years & 43 & 3.17 & 0.46 & & \\
5 - 10 years & 108 & 3.21 & 0.46 & & \\
11 - 15 years & 28 & 3.16 & 0.39 & & \\
$>15$ years & 4 & 3.23 & 0.31 & & \\
\hline
\end{tabular}

${ }^{1}$ One way ANOVA.

having positive core (mean $\geq 3.0$ or $\geq 60.0 \%$ ) except in the domain of "frequency of event reported" and "hospital handoffs \& transitions", which was below mean score of $3.0(60.0 \%)$. These results are not consistent with the results of Rajalatchumi et al. [12], which revealed that the total composite positive perception of patient safety culture among healthcare providers was found to be $58 \%$.

In the present study, it has been identified that the study participants demonstrated a positive perception on the majority of study aspects. These results are consistent with those of the previous studies in which the overall patient safety grade for the hospital was considered as outcome variable [13], and patient safety culture was good in the majority of patient safety culture domains Escoval et al. [14].

Regarding the differences in the mean level of perception with regard to nurses' demographic factors, these results are not consistent with the results of Okuyama et al. [11] which revealed that greater age and length of work experience were associated with higher perceptions of patient safety culture in the 
domains of "supervisor/manager expectations and actions promoting patient safety", "organizational learning and continuous improvement", "frequency of events reported", "feedback and communication about error", "staffing" and "management support for patient safety".

\section{Conclusion}

The study revealed positive perception regarding patient safety culture in the majority of patient safety domains except in the domain of "frequency of events reported" and "hospital handoffs and transitions". Thus the issues related to reporting events and hospital handoffs and transitions need to be enhanced and improved.

\section{Limitations of the Study}

The study included only the nurses; however the inclusion of other participants such as physicians and other healthcare providers could give important results, since the issue of patient safety is the responsibility of all healthcare providers.

\section{Conflicts of Interest}

The authors declare no conflicts of interest regarding the publication of this paper.

\section{References}

[1] Fernandes Agreli, H., Murphy, M., Creedon, S., Ni Bhuachalla, C., O’Brien, D., Gould, D., Savage, E., Barry, F., Drennan, J., Smiddy, M. P., Condell, S., Horgan, S., Murphy, S., Wills, T., Burton, A. and Hegarty, J. (2019) Patient Involvement in the Implementation of Infection Prevention and Control Guidelines and Associated Interventions: A Scoping Review. BMJ Open, 9, e025824. https://doi.org/10.1136/bmjopen-2018-025824

[2] Gandhi, T.K., Berwick, D.M. and Shojania, K.G. (2016) Patient Safety at the Crossroads. JAMA, 315, 1829-1830. https://doi.org/10.1001/jama.2016.1759

[3] Wallis, K. and Dovey, S. (2011) Assessing Patient Safety Culture in New Zealand Primary Care: A Pilot Study Using Manchester Patient Safety Framework. Journal of Primary Health Care, 3, 35-40. https://doi.org/10.1071/HC11035

[4] Kaufman, G. and Mc Caughan, D. (2013) The Effect of Organisational Culture on patient Safety. Nursing Standard, 27, 50-56. https://doi.org/10.7748/ns2013.06.27.43.50.e7280

[5] Weaver, S.J., Lubomksi, L.H., Wilson, R.F., Pfoh, E.R., Martinez, K.A. and Dy, S.M. (2013) Promoting a Culture of Safety as a Patient Safety Strategy: A Systematic Review. Annals of Internal Medicine, 158, 369-374. https://doi.org/10.7326/0003-4819-158-5-201303051-00002

[6] Dodek, P.M., Wong, H., Heyland, D.K., et al. (2012) The Relationship between Organizational Culture and Family Satisfaction in Critical Care. Critical Care Medicine, 40, 1506-1512. https://doi.org/10.1097/CCM.0b013e318241e368

[7] Washington State Department of Health (2014) Adverse Events.

[8] Aboshaiqah, A.E. and Baker, O.G. (2013) Assessment of Nurses' Perceptions of Patient safety Culture in a Saudi Arabia Hospital. Journal of Nursing Care Quality, 28, 
272-280. https://doi.org/10.1097/NCQ.0b013e3182855cde

[9] Eldeeb, G.A., Ghoneim, A.A. and Eldesouky, E.K. (2016) Perception of Patient Safety among Nurses at Teaching Hospital. American Journal of Nursing Science, 5, 122-128. https://doi.org/10.11648/j.ajns.20160504.11

[10] Alshammari, F., Pasay-an, E., Alboliteeha, M., et al. (2019) A Survey of Hospital Healthcare Professionals' Perceptions toward Patient Safety Culture in Saudi Arabia. International Journal of Africa Nursing Sciences, 11, Article ID: 100149. https://doi.org/10.1016/j.ijans.2019.100149

[11] Okuyama, J.H.H., Galvão, T.F., Crozatti, M.T.L. and Silva, M.T. (2019) Health Professionals' Perception of Patient Safety Culture in a University Hospital in São Paulo: A Cross-Sectional Study Applying the Hospital Survey on Patient Safety Culture. Sao Paulo Medical Journal, 137, 216-222. https://doi.org/10.1590/1516-3180.2018.0430140319

[12] Rajalatchumi, A., Ravikumar, T.S., Muruganandham, K., Thulasingam, M., Selvaraj, K., Reddy, M.M. and Jayaraman, B. (2018) Perception of Patient Safety Culture among Health-Care Providers in a Tertiary Care Hospital, South India. Journal of Natural Science, Biology, and Medicine, 9, 14-18.

https://doi.org/10.4103/jnsbm.JNSBM_86_17

[13] Siddharth, V., Koushal, V. and Goyal, A. (2017) Patient Safety Is the Need of the Hour: A Study in Nursing Department of a Tertiary Care Teaching Hospital. International Journal of Research Foundation of Hospital \& Healthcare Administration, 5, 55-59. https://doi.org/10.5005/jp-journals-10035-1076

[14] Escoval, A., Grillo, I. and Silva-fortes, C. (2014) The Hospital Survey on Patient Safety Culture in Portuguese Hospitals. International Journal of Health Care Quality Assurance, 27, 111-122. https://doi.org/10.1108/IJHCQA-07-2012-0072 